\title{
Krampfadern: strippen besser als lasern?
}

\author{
Krampfadern lassen sich entwe- \\ der per Stripping oder per en- \\ dovenöser Lasertherapie (EVLT) \\ entfernen. Bisher gibt es nur weni- \\ ge Studien, in denen die Effektivität \\ der beiden Methoden verglichen \\ wird.
}

- Beim Lasern wird die Hauptvene verödet. Kleine Seitenäste bleiben aber offen und können Ausgangspunkt für Krampfaderrezidive sein. Beim Stripping werden auch diese Seitenäste entfernt. Vorteil der EVLT ist die geringere Invasivität des Eingriffs.

Wissenschaftler der Universität des Saarlandes in Homburg teilten 400 Varikose-Patienten 1:1 per Los zufällig in zwei Gruppen. Die eine Gruppe wurde dem Stripping unterzogen, die andere der EVLT. Nach zwei Jahren wurde der Zustand der Patienten überprüft.

Die Rate an klinisch manifesten Krampfaderrezidiven betrug $16 \%$ in der Laser- und 23\% in der Strippinggruppe. Der Unterschied war nicht signifikant.

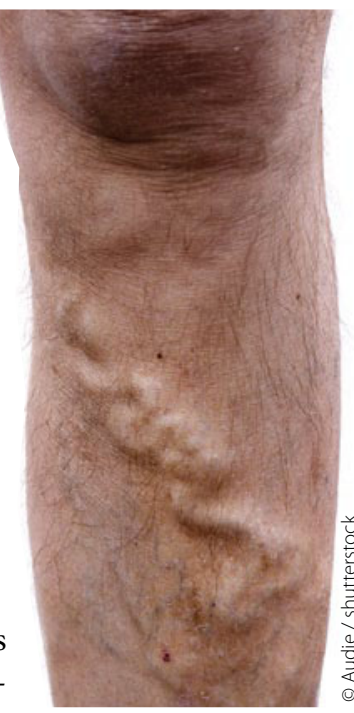

Varikosis: nicht
nur ein kosme-
tisches Problem.

Drei Monate nach dem Eingriff klagten die Laserpatienten etwas seltener über Schmerzen als die Strippingpatienten. Auch war das kosmetische Ergebnis nach dem Lasereingriff besser als nach dem Stripping. Sonst unterschied sich die Zufriedenheit der Patienten mit dem Ergebnis in beiden Gruppen nicht.

Einen signifikanten Unterschied zwischen den beiden Gruppen fanden die Forscher aber doch: Mittels Duplexsonografie wurde bei 17,8\% der Laserpati- enten ein saphenofemoraler Reflux nachgewiesen aber nur bei $1,3 \%$ der Strippingpatienten. Wie dieser Befund das Langzeitergebnis beeinflusst, sollen weiter Studien herausfinden.

\section{Kommentar}

Die Studie zeigt zunächst, dass Stripping und EVLT in etwa gleichwertige Methoden zur Behandlung von Krampfadern sind. $\mathrm{Ob}$ sich Stripping im Langzeitergebnis vielleicht doch als überlegen erweist, muss sich erst noch zeigen.

K. MALBerG .

\footnotetext{
- K. Rass et al.

(Dept. Dermatol., Venerol. and Allergol., Universitätsklinikum des Saarlandes, 66421 Homburg /Saar, Germany; E-mail: knuth.rass@uks.eu ). Comparable effectiveness of endovenous laser ablation and high ligation with stripping of the great saphenous vein. Two-year results of a randomized clinical trial (RELACS study) Published first on Sept. 19, 2011 in Arch. Dermatol., doi: 10.1001/archdermatol.2011.272
}

\section{Magerjoghurt während der Schwangerschaft erhöht das Asthmarisiko beim Kind}

\begin{abstract}
Aus Angst vor einer unkontrollierten Gewichtszunahme ernähren sich viele Schwangere besonders kalorienbewusst. So bevorzugen sie etwa fettarme Milchprodukte. Jetzt wurde untersucht, ob sich dies auf die spätere Entwicklung des Kindes auswirkt.
\end{abstract}

— Die Forscher ermittelten aus verschiedenen Quellen, Melderegistern oder einer dänischen Geburtenkontroll-Untersuchung des Staten Serum Instituts Kopenhagen von über 70000 Kindern, wie häufig Asthma und Heuschnupfen im 7. Lebensjahr auftraten. Gesucht wurde auch nach einer Korrelation zwischen diesen Erkrankungen und den Ernäh- rungsgewohnheiten der Mütter während der Schwangerschaft.

Magermilch per se schien nicht in Verbindung mit einem erhöhten Asthmarisiko zu stehen. Anders sah das Ergebnis für Magerjoghurts aus: Wenn eine Schwangere pro Tag einen fettreduzierten Joghurt aß, erhöhte sich das Risiko, dass ihr Kind bis zum Alter von sieben Jahren Asthma entwickelte, um den Faktor 1,6. Die Kinder bekamen darüber hinaus auch häufiger Heuschnupfen.

\section{Kommentar}

Eine vernünftige Erklärung zwischen dem Konsum von Magerjoghurt und dem erhöhten Asthmarisiko bei den Kindern gibt es bisher nicht. Es könnte sein, dass dem Joghurt mit dem Fett bestimmte, noch nicht identifizierte Nährstoffe entzogen werden, die einen gewissen Schutz vor allergischen Atemwegserkrankungen bedingen. Sicher nicht verkehrt ist der Rat von Gynäkologen, dass Frauen, die vorhaben, während der Schwangerschaft ihre Ernährung umzustellen, dies erst einmal mit ihrem Arzt besprechen sollten.

K. MALBERG

\section{- E. Maslova et al.}

Low-fat yogurt intake when pregnant linked to increased risk of child asthma and hay fever. European Respiratory Society's (ERS) Annual Congress, Amsterdam (25 September 2011). 